American Journal of Applied Sciences 9 (1): 13-17, 2012

ISSN 1546-9239

(C) 2012 Science Publications

\title{
Diagnostic Features and Therapeutic Consequences of Hysteroscopy in Women with Abnormal Uterine Bleeding and Abortion
}

\author{
Sedigheh Abdollahi Fard, Farnaz Sahaf Ebrahimi, \\ Farnaz Montazeri and Omid Mashrabi \\ Department of Obstetrics and Gynecology, \\ Women's Reproductive Health Research Center, \\ Faculty of Medicine, Tabriz University of Medical Sciences, Tabriz, Iran
}

\begin{abstract}
Problem statement: Hysteroscopy is a procedure in which the endometrial cavity is observable and subject of manipulation via transcervical route. Hysteroscopy is a minimally invasive process in diagnosis and treatment of many intrauterine and endocervical conditions. Polypectomy, myomectomy and endometrial ablation could be easily manageable by this procedure. According to safety and high efficiency of hysteroscopy, this method is changing to a widespread procedure in dealing with many gynecologic and obstetrical conditions. This study aimed at evaluating the diagnostic and therapeutical efficiency of hysteroscopy in managing of common conditions including abnormal uterine bleeding and abortion. Approach: In a descriptive cross-sectional setting, 243 women underwent hysteroscopy were evaluated in two groups: with uterine bleeding 236 cases and with recurrent abortions 7 cases. This study was conducted in Tabriz Alzahra Educational Center during a 15 -month period. The main causes of the complaints were determined in each group. Six months after treatment, the overall success rate was recorded. Results: Hysteroscopy was the sole diagnostic procedure in 16.5 and $14.3 \%$ of the patients in groups with abnormal uterine bleeding and abortion, respectively. In the group with abnormal uterine bleeding, curettage, myomectomy, polypectomy, hysterectomy, laparoscopy and laparotomy were the main diagnostic-therapeutical approaches along with the hysteroscopy in descending order. In the group with recurrent abortion, laparoscopy, curettage and myomectomy were the main diagnostic-therapeutical approaches along with the hysteroscopy in descending. There was not any major complication. The diagnostic-therapeutical measures accompanying with the laparoscopy were successful in $73.5 \%$ of the bleeding group in follow-up period. Conclusion: Based on our results, hysteroscopy is a safe, accurate and highly-efficient procedure in managing women with abnormal uterine bleeding and recurrent abortion.
\end{abstract}

Key words: Hysteroscopy, recurrent Abortion, uterine bleeding, diagnostic-therapeutical, therapeutic method, treatment type, endometrial cavity, laparoscopy

\section{INTRODUCTION}

Hysteroscopy is a method through which endometrial cavity can be observed and manipulated transcervically. Hysteroscopy is considered a minimally invasive approach which can be used for data analysis and treatment of numerous intrauterine and endocervical problems (Loffer et al., 2000; Nabila et al., 2009). In many developed countries, hysteroscopy has replaced curettage in diagnosing and if possible treating abnormal uterine bleeding sources. The advantage of this method is the direct view and simultaneous intervention (Bradley et al., 2000; Cooper and Brady, 1999). Mullerian system abnormalities are the most common intrauterine disorders which are associated with infertility problems and spontaneous abortion. These disorders are related to developmental defects (agenesis, unicorn uterus), junction defects (bicornuate uterus) or defects in tube canalization (septated uterus) (Breek, 2002). Primary diagnosis is difficult due to the wide range of symptoms in these disorders including menstruation bleeding occlusion in the beginning of puberty, hypermenorrhea, vaginal discharges,

Corresponding Author: Sedigheh Abdollahi Fard, Department of Obstetrics and Gynecology,

Women's Reproductive Health Research Center, Faculty of Medicine,

Tabriz University of Medical Sciences, Tabriz, Iran Tel: +98-9141157141 
dyspareunia, infertility and abortion. Diagnostic measurements are based on hysterosalpingography, laparoscopy, hysteroscopy and sonography. Many of the disorders can be observed primarily in hysterosalpingography and sonogram but to be approved further imaging is a required. In these cases, MRI is considered the first option. Laparoscopy and hysteroscopy are kept for the patients needing interventional treatments (Baggish et al., 1999). Considering the efficacy and safety of hysteroscopy in diagnosing and treating many common obstetrical and gynecological conditions, expanding this method in our centers is an essential; a fact that has not been focused on so far. Therefore, in this study we are to evaluate the diagnostic and therapeutic efficacy of hysteroscopy in the common positions like abnormal uterine bleeding and abortion.

\section{MATERIAL AND METHODS}

In the descriptive -analytic study carried out in Tabriz Alzahra Hospital from 2008-2009, the hysteroscopy results of 243 patients were studied. In this study 243 patients referred with the complications of vaginal bleeding (236 cases) and the recurrent abortions ( 7 cases) were divided into three groups.

Underlying reasons of abnormal uterine bleeding and abortion were clarified in hysteroscopy and their frequency in each group was determined based on the treatment type. Patients being treated using hysteroscopy were fallowed six months after treatment and success rates were determined. In evaluating treatment results, the patients were included in the study that could be followed up at least six months after treatment. Knowing that this diagnostic and therapeutic method is performed routinely for qualified patients in Alzahra educational therapeutic center and no extra intervention was performed, no specific ethical problem was faced. Patients' data remained confidential. This study has been approved by Tabriz medical science University ethics committee. The following variables were studied: age, gravidity, parity, history of previous abortion, number of abortions, duration of the complaints, hospitalization time, contraceptive type, menstruation status, treatment type and complications or failure of diagnosis-treatment.

\section{RESULTS}

243 females who were performed hysteroscopy were divided into three groups: 236 cases with vaginal bleeding and 7 cases of recurrent abortions. The characteristics of patients are presented in Table 1 and Fig. 1. Treatment type in three groups is summarized in Table 2.
Table 1: Demographic parameters of patients

\begin{tabular}{llllc}
\hline & & $\begin{array}{l}\text { Recurrent } \\
\text { abortions }\end{array}$ & $\begin{array}{l}\text { Uterine } \\
\text { bleeding }\end{array}$ & P_value \\
\hline Age (year) & & $32.7+6$ & $41.3+8.3$ & $<0.001$ \\
Gravidity & & $4.4 \pm 1.4$ & $3.8 \pm 2.5$ & 0.536 \\
Parity & & $1.4 \pm 1.6$ & $3.3 \pm 2.3$ & 0.029 \\
Abortion & & $3.3 \pm 2.0$ & $0.6 \pm 1.2$ & 0.011 \\
Admitted duration & & $2.9 \pm 0.7$ & $3.1 \pm 1.4$ & 0.691 \\
Prevention & No & $1(14.3 \%)$ & $39(16.5 \%)$ & - \\
& Tubal ligation & 0 & $72(30.5 \%)$ & \\
& Vasectomy & 0 & $9(3.8 \%)$ & \\
& Withdraw & $2(28.6 \%)$ & $55(23.3 \%)$ & \\
& Candom & 0 & $24(10.2 \%)$ & \\
& OCP & $4(57.1 \%)$ & $17(7.2 \%)$ & \\
Period & Intra uterine device & 0 & $20(8.5 \%)$ & \\
& Regular & $5(71.4)$ & $74(31.6 \%)$ & - \\
& Irregular & $1(14.3 \%)$ & $140(59.3 \%)$ & \\
& Absent & $1(14.3 \%)$ & $3(1.3 \%)$ & \\
& Menopause & 0 & $19(8.1 \%)$ & \\
\hline
\end{tabular}

Table 2: types of treatment in three groups

\begin{tabular}{lll}
\hline & $\begin{array}{l}\text { Recurrent } \\
\text { abortions }\end{array}$ & $\begin{array}{l}\text { Uterine } \\
\text { bleeding }\end{array}$ \\
\hline Hysteroscopy & $1(14.3 \%)$ & $39(16.5 \%)$ \\
Hysteroscopy and myiomectomy & $1(14.3 \%)$ & $19(8.1 \%)$ \\
Hysteroscopy and curettage & $2(28.6 \%)$ & $88(37.3 \%)$ \\
Hysteroscopy and polypectomy & 0 & $6(2.5 \%)$ \\
$\begin{array}{l}\text { Hysteroscopy, curettage and polypectomy } \\
\text { Hysteroscopy and hysterectomy }\end{array}$ & 0 & $12(5.1 \%)$ \\
Hysteroscopy and laparoscopy & 0 & $14(5.9 \%)$ \\
Hysteroscopy and laparotomy & $3(42.9 \%)$ & $11(4.7 \%)$ \\
Hysteroscopy, myiomectomy & 0 & $3(1.3)$ \\
$\begin{array}{l}\text { and curettage } \\
\text { Hysteroscopy, myiomectomy } \\
\text { and polypectomy }\end{array}$ & 0 & $36(15.3 \%)$ \\
\end{tabular}

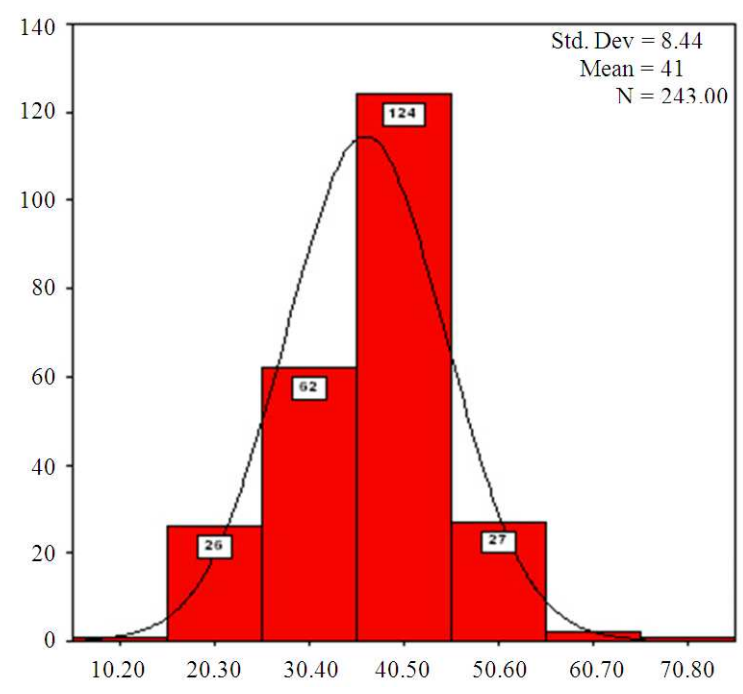

Fig. 1: Scattering age of patients

Complications related to hysteroscopy were not seen in any of the patients. In the group of vaginal bleeding, 34 patients could be followed up. In the recurrent abortion group none of the cases could be followed up. 
Am. J. Applied Sci., 9 (1): 13-17, 2012

\section{DISCUSSION}

In this study, we evaluated the diagnostic and therapeutic results of hysteroscopy in females with abnormal uterine bleeding and recurrent abortion.

Abnormal uterine bleeding: In the group of abnormal uterine bleeding, hysteroscopy was used as the only diagnostic method in $16.5 \%$ of the cases. In this group the most common diagnostic therapeutic method combined with hysteroscopy were curettage, myomectomy, polypectomy, hysterectomy, laparoscopy and laparotomy. No complication was observed and in $73.5 \%$ of the cases diagnostic and therapeutic measures had led to the treatment of uterine bleeding. In the study of Liu et al. (2007) which was carried out on 35 females with abnormal uterine bleeding, the treatments using hysteroscopy were successful in $85.7 \%$ of the cases (Liu et al., 2007). In the study of Engelsen et al. (2006) which was carried out on 386 females with abnormal uterine bleeding, hysteroscopy was successful in $83.4 \%$ of the cases (Engelsen et al., 2006). In the study of Loffer et al. (2000) which was carried out on the 177 females with abnormal uterine bleeding, hysteroscopy in $95.9 \%$ of the cases was successful regarding diagnosis and treatment (Loffer, 2005). As it can be seen, the results obtained from our study are in accordance with the results obtained from similar studies. Van Dongen et al. (2009) in a study carried out on 21 patients with abnormal uterine bleeding used hysteroscopy as a diagnostic or therapeutic method. The underlying reason was uterine polyp in most of the cases which was treated properly (Van Dongen et al., 2009). Fuentes et al. (2007) in a study carried out on 5103 cases of hysteroscopy due to abnormal uterine bleeding diagnosed and treated 641 cases of endometrial polyps. Only in one case was there a report of seizure and in another case uterine perforation as diagnostic-therapeutic complications (Fuentes, 2007). In another study carried out by Alanis Fuentes et al. (2007), 372 females in the age of menopause with abnormal uterine bleeding were studied. Uterine atrophy, polyp, cancer and hyperplasia were the most common causes of bleeding respectively. In this study, hysteroscopy was introduced as a prime diagnostic and therapeutic method in this group of patients (Fuentes et al., 2007). In the study of Lasmar et al. (2008), 4054 cases of hysteroscopy combined with biopsy were studied. In this study also endometrial polyp was introduced as the most common cause of abnormal uterine bleeding (Lasmar et al., 2008). Cravello et al. (2004) in a study introduced hysteroscopy as the golden standard of treating uterine bleeding caused by uterine myomas (Cravello et al., 2004). Mukhopadhayay et al. (2007) in a study compared three methods of transvaginal sonography, hysteroscopy and endometrial biopsy regarding the diagnosis of the reasons causing abnormal uterine bleeding. Finally it should be mentioned that hysteroscopy is the most specific and sensitie diagnostic modality for endometrial polyps (Mukhopadhayay et al., 2007). As it was previously mentioned, most diagnosed patients in this study were performed polypectomy, myomectomy or curettage which is suggestive of the high incidence of benign uterine lesions as underlying bleeding sources. The results obtained from this study are in accordance with the results obtained from similar studies, i.e., hysteroscopy is a safe and efficient diagnostic-therapeutic method in evaluating and treating this group of patients.

Recurrent abortion: In the recurrent abortion group, hysteroscopy was used as the only diagnostic method in $14.3 \%$ of the cases. In this group, Laparoscopy, curettage and myomectomy were the most common associated diagnostic-therapeutic measures respectively. Filho et al. (2006a), in two studies, demonstrated that this method is efficient in the diagnosis of abortion causes and in the treatment of possible cases (Filho et al., 2006a). Filho et al. (2006b). Dendrinos et al. (2008) studied 48 infertile females. In $52 \%$ of the cases hysteroscopy was normal. In the rest of the cases, myomas, adhesion, polyp and structural disorders were reported. In this study, hysteroscopy was introduced as a safe and efficient diagnostic-therapeutic method in these patients (Dendrinos et al., 2008). In the study of Ventolini et al. (2004), 23 patients with recurrent abortions were studied. In $60.9 \%$ of the cases, there were no abnormal findings. In the rest of the cases structural uterine disorders, myomas, adhesion were reported. Pregnancy ratio was 29\% after treatment (Ventolini et al., 2004). Weiss et al. (2005), in a study, concluded that hysteroscopy is indicated in every female with two abortions (Weiss et al., 2005). The results obtained from our study are accordance with the similar studies however the number of patients with recurrent abortions is low in the present study.

\section{CONCLUSION}

Hysteroscopy was used as the only diagnostic method in the groups with abnormal uterine bleeding and recurrent abortions in 16.5 and $14.3 \%$ of the cases. In the group of abnormal uterine bleeding, curettage, myomectomy, polypectomy, hysterectomy, laparoscopy 
and laparotomy were the most common diagnostictherapeutic approaches combined with hysteroscopy respectively. In the group with recurrent abortion, laparoscopy, curettage and myomectomy were the most common diagnostic-therapeutic approaches combined with hysteroscopy respectively. No major complication was reported in any of the patients. In the follow-up of patients, bleeding cessation and pregnancy was reported in two groups with abnormal uterine bleeding in $73.5 \%$.

Based on the results obtained from the present study, hysteroscopy is a safe and efficient method in diagnosis and treatment of the causes leading to abnormal uterine bleeding and recurrent abortions and therefore it should be used as a less invasive method in the management of these patients. Further prospective studies with higher sample volumes are needed to reach more precise results on the efficacy of hysteroscopy in the patients with recurrent abortions.

\section{REFERENCES}

Baggish, M.S., J. Barbot and R.F. Valle, 1999. Diagnostic and Operative Hysteroscopy: A Text and Atlas. 2nd Edn., Mosby, USA., pp: 401.

Bradley, L.D., T. Falcone and A.B. Magen, 2000. Radiographic imaging techniques for the diagnosis of abnormal uterine bleeding. Obstet. Gynecol. Clin. North Am., 27: 245-276. PMID: 10857118.

Breek, J.S., 2002. Novak's Gynecology. 13th Edn., Lippincott Williams and Wilkins, USA., ISBN: 9780781741538, pp: 1200.

Cooper, J.M. and R.M. Brady, 1999. Hysteroscopy in the management of abnormal uterine bleeding. Obstet. Gynecol. Clin. North Am., 26: 217-236. PMID: 10083940

Cravello, L., A. Agostini, M. Beerli, V. Roger and F. Bretelle et al., 2004. Results of hysteroscopic myomectomy. Gynecol. Obstet. Fertil., 32: 825828. PMID: 15380769

Dendrinos, S., O. Grigoriou, E.G. Sakkas, E. Makrakis and G. Creatsas, 2008. Hysteroscopy in the evaluation of habitual abortions. Eur. J. Contracept Reprod. Health Care, 13: 198-200. PMID: 18465483.

Engelsen, I.B., K. Woie and K. Hordnes, 2006. Transcervical endometrial resection: Long-term results of 390 procedures. Acta Obstet. Gynecol. Scand., 85: 82-87. PMID: 16521686

Filho, H.A.G., R. Mattar, C.R. Pires, E.A. Junior and A.F. Moron et al., 2006a. Comparison of hysterosalpingography, hysterosonography and hysteroscopy in evaluation of the uterine cavity in patients with recurrent pregnancy losses. Arch. Gynecol. Obstet., 274: 284-288. PMID: 16819615
Filho, H.A.G., R. Mattar, E.A. Junior, C.R. Pires and A.F. Moron, 2006b. Diagnosis of uterine synechiae in patients with recurrent miscarriages: Contribution of transvaginal hysterosonography. Rev. Assoc. Med. Bras., 52: $308-311 . \quad$ PMID: 17160303

Fuentes, J.A., 2007. In-office hysteroscopic polypectomy: Eight years analysis. Ginecol. Obstet. Mex., 75: 341-346. PMID: 18297859

Fuentes, J.A., M.M. Gutierrez and M.P. Mata, 2007. Hysteroscopy findings in patients with postmenopausal genital bleeding. Ginecol. Obstet. Mex., 75: 253-258. PMID: 17849807

Lasmar, R.B., R. Dias, P.R. Barrozo, M.A. Oliveira and S.E. Coutinho et al., 2008. Prevalence of hysteroscopic findings and histologic diagnoses in patients with abnormal uterine bleeding. Fertil Steril, 89: 1803-1807. PMID: 17889860

Liu, Y., Y. Cheong, T.C. Li, E. Xia, D. Zhang and Y. $\mathrm{Ma}, 2007$. Impact of transcervical resection of endometrium on uterine and ovarian haemodynamics. Reprod. Biomed. Online, 15: 5762. PMID: 17623536

Loffer, F.D., 2005. Improving results of hysteroscopic submucosal myomectomy for menorrhagia by concomitant endometrial ablation. J. Minim. Invasive Gynecol., 12: 254-260. PMID: 15922984

Loffer, F.D., L.D. Bradley, A.I. Brill, P.G. Brooks and J.M. Cooper, 2000. Hysteroscopic training guidelines. The ad hoc committee on hysteroscopic training guidelines of the American association of gynecologic laparoscopists. J. Am. Assoc. Gynecol. Laparosc., 7: 165-165. PMID: 10648761

Mukhopadhayay, S., S.K. Bhattacharyya, R.P. Ganguly, K.K. Patra and N. Bhattacharya et al., 2007. Comparative evaluation of perimenopausal abnormal uterine bleeding by transvaginal sonography, hysteroscopy and endometrial biopsy. J. Indian Med. Assoc., 105: 624, 626, 628. PMID: 18405088

Nabila, K.Y., E.M. Yaseen and R.S. Tawfeek, 2009. A comparative study between abdominal and laparoscopic diathermy in evaluation of ovulatory response in women with polycystic ovary syndrome. Am. J. Pharmacol. Toxicol., 4: 165-168. DOI: 10.3844/ajptsp.2009.165.168

Van Dongen, H., C.A. Janssen, M.J. Smeets, M.H. Emanuel and F.W. Jansen, 2009. The clinical relevance of hysteroscopic polypectomy in premenopausal women with abnormal uterine bleeding. BJOG, 116: 1387-1390. PMID: 19691630 
Ventolini, G., M. Zhang and J. Gruber, 2004. Hysteroscopy in the evaluation of patients with recurrent pregnancy loss: A cohort study in a primary care population. Surg. Endosc., 18: 17821784. PMID: 15809790
Weiss, A., E. Shalev and S. Romano, 2005.

Hysteroscopy may be justified after two

miscarriages. Hum. Reprod., 20: 2628-2631.

PMID: 15890730 